\title{
Correction to: Nal cubic detector full-energy peak efficiency, including coincidence and self-absorption corrections for rectangular sources using analytical method
}

\author{
Mahmoud I. Abbas ${ }^{1} \cdot$ Mohamed Elsafi $^{1}$ (1) - Mona M. Gouda ${ }^{1} \cdot$ Mohamed Abd-Elzaher $^{2} \cdot$ A. Hamzawy ${ }^{3}$. \\ Mohamed S. Badawi ${ }^{4}$. Abouzeid A. Thabet ${ }^{5} \cdot$ Salam Noureddine ${ }^{6} \cdot$ Ahmed M. El-Khatib $^{1}$
}

Published online: 20 February 2021

(c) Akadémiai Kiadó, Budapest, Hungary 2021

\section{Correction to: \\ Journal of Radioanalytical and Nuclear Chemistry. https://doi.org/10.1007/s10967-020-07508-8}

The affiliation of a co-author Mohamed. S. Badawi was erroneously printed.

The correct affiliation appears in this correction.

Publisher's Note Springer Nature remains neutral with regard to jurisdictional claims in published maps and institutional affiliations.

The original article can be found online at https://doi.org/10.1007/ s10967-020-07508-8.

Mohamed Elsafi

mohamedelsafi68@gmail.com

1 Physics Department, Faculty of Science, Alexandria,

University, Alexandria 21511, Egypt

2 Department of Basic and Applied Sciences, Faculty of Engineering, Arab Academy for Science, Technology and Maritime Transport, Alexandria, Egypt

3 Physics Department, Al-Jamoum University College, Umm Al-Qura University, Al-Jamoum, Saudi Arabia

4 Physics Department, Faculty of Science, Beirut Arab University, Beirut, Lebanon

5 Department of Medical Equipment Technology, Faculty of Allied Medical Sciences, Pharos University, Alexandria, Egypt

6 Physics Department, Faculty of Science, Lebanese University, Beirut, Lebanon 